Licença CC BY: Artigo distribuído

sob os termos

Creative Commons, permite uso e distribuição irrestrita em qualquer meio desde que $o$ autor credite a fonte original.

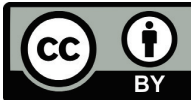

\section{O TURISMO NO CENTRO HISTÓRICO DE FLORIANÓPOLIS (SC): UM ESTUDO REALIZADO NO FACEBOOK SOB A ÓTICA DOS 4 A'S DO BENCHMARKING}

\author{
TOURISM IN THE HISTORIC CENTER OF FLORIANÓPOLIS (SC): A \\ STUDY CONDUCTED ON FACEBOOK FROM THE PERSPECTIVE OF \\ THE 4 AS OF BENCHMARKING
}

TURISMO EN EL CENTRO HISTÓRICO DE FLORIANÓPOLIS (SC): UN ESTUDIO REALIZADO EN FACEBOOK DESDE LA PERSPECTIVA DE LAS 4 A'S DE BENCHMARKING

\author{
DIVA DE MELLO ROSSINI' \\ JOSILDETE PEREIRA DE OLIVEIRA ${ }^{1}$ \\ RODOLFO WENDHAUSEN KRAUSE' \\ GABRIELA SANTOS CAPELLA ${ }^{1}$
}

\author{
'UNIVERSIDADE DO VALE DO ITAJAÍ, BALNEÁRIO CAMBORIÚ, SANTA \\ CATARINA, BRASIL
}

\begin{abstract}
RESUMO: O objetivo deste estudo foi analisar as vitrines de marketing de empresas de turismo que divulgam o centro histórico de Florianópolis (SC) como um atrativo turístico, no Facebook, utilizando como metodologia os 4 A'S (acessibilidade, atração, animação e ação) da matriz do Modelo Inglês de Benchmarking e como ferramenta para análise de dados o software Iramuteq. A hipótese formulada foi confirmada. As vitrines apresentam dados da matriz dos 4 A's do Modelo Inglês de Benchmarking e as informações são divulgadas sob a forma de Roteiros Turísticos, os quais associam os atrativos turísticos culturais do Centro Histórico a outros atrativos turísticos culturais e naturais, como paisagens e praias. Importante salientar a relevância dada à divulgação do meio de transporte terrestre e dos períodos que ele é disponibilizado. Os resultados obtidos poderão contribuir com a elaboração/qualificação das vitrines de marketing de empresas de turismo que divulgam os centros históricos das cidades, com a criação de movimentos que resultem na criação de políticas públicas em prol da preservação/conservação do patrimônio cultural e com o desenvolvimento do turismo cultural, promovendo oportunidades para o crescimento da renda para as entidades públicas, privadas e para os residentes.
\end{abstract}

DIVA Professora do curso de Pós-graduação em Turismo e Hotelaria, Universidade do Vale do Itajaí, Balneário Camboriu, Santa Catarina, Brasil. Doutorado, Univerisadade do Vale do Itajaí, Univerisadade do Vale do Itajaí, Balneário Camboriu, Santa Catarina, Brasil. E-mail:divarossini@univali.br . Orcid: https://orcid. org/0000-0002-9050-6587.

JOSILDETE Professora do curso de Pós-graduação em Turismo e Hotelaria, Universidade do Vale do Itajaí, Balneário Camboriu, Santa Catarina, Brasil. Doutorado, Université de Caen Basse Normandie, Normandia, França. E-mail:joliveira@univali.br . Orcid: https://orcid.org/0000-0001-8488-1869.

RODOLFO Professor do curso de Pós-graduação em Turismo e Hotelaria, Universidade do Vale do Itajaí, Balneário Camboriu, Santa Catarina, Brasil. Doutorado, Univerisadade do Vale do Itajaí, Universidade do Vale do Itajaí, Balneário Camboriu, Santa Catarina, Brasil. E-mail:rodolfo@univali.br . Orcid: https://orcid. org/0000-0002-5382-7680

GABRIELA Academica do curso de graduação em Arquitetura e Urbanismo, Universidade do Vale do Itajaí, Balneário Camboriu, Santa Catarina, Brasil. E-mail: gabrielacapella1998@hotmail.com . Orcid: https:// orcid.org/0000-0002-3818-4613 
PALAVRAS-CHAVES: Vitrines de Marketing. Facebook. Centro Histórico de Florianópolis (SC). 4 A's do Benchmarking.

ABSTRACT: The aim of this study was to analyze the marketing windows of tourism companies that advertise the historic center of Florianópolis (SC) as a tourist attraction, on Facebook, using the methodology of the 4 As (accessibility, attraction, animation and action) matrix of the English Benchmarking Model, and the Iramuteq computer program for the data analysis. The hypothesis formulated was confirmed. The marketing windows present data that reflect the 4 As matrix, with the information being advertised in the form of Tourist Routes that associate the cultural tourist attractions of the Historic Center with other cultural and natural tourist attractions, such as landscapes and beaches. It is important to highlight the importance of advertising the means of land transport, and the periods it is available. It is hoped that the results of this study will contribute to the elaboration/qualification of marketing windows of tourism companies that advertise the historic centers of cities, creating movements to promote new public policies in favor of the preservation/conservation of cultural heritage and with the development of cultural tourism, and creating opportunities for income growth for public and private entities and residents.

KEYWORDS: Marketing showcases. Facebook. Florianópolis Historic Center (SC). 4 As of Benchmarking.

RESUMEN: El objetivo de este estudio fue analizar las ventanas de comercialización de las empresas turísticas que anuncian el centro histórico de Florianópolis (SC) como una atracción turística, en Facebook, utilizando como metodología las 4 A'S (accesibilidad, atracción, animación y acción) de la base Modelo Inglés de Benchmarking y como herramienta para el análisis de datos el software Iramuteq. La hipótesis formulada fue confirmada. Las vitrinas presentan datos de la base 4 A's del Modelo Inglés de Benchmarking y, las informaciones se difunden en forma de rutas turísticas, que asocian las atracciones turísticas culturales del Centro Histórico con otras atracciones turísticas culturales y naturales, como paisajes y playas. Es importante resaltar la relevancia dada a la divulgación de los medios de transporte terrestre y los períodos en que está disponible. Los resultados obtenidos pueden contribuir a la elaboración / calificación de las ventanas de comercialización de las empresas turísticas que publicitan los centros históricos de las ciudades, con la creación de movimientos que resultan en la creación de políticas públicas a favor de la preservación / conservación del patrimonio cultural y con el desarrollo del turismo cultural, promoviendo oportunidades de crecimiento de ingresos para entidades públicas y privadas y residentes.

PALABRAS CLAVE: Vitrinas de marketing. Facebook. Centro histórico de Florianópolis (SC). 4 A's del Benchmarking's.

\section{INTRODUÇÃO}

Esta investigação foi desenvolvida a partir das metodologias utilizadas pelos grupos de pesquisa Turismo, Hospitalidade e Gastronomia e Planejamento e Gestão do Espaço Turístico, sendo os pesquisadores proponentes integrantes destes grupos consolidados e certificados pelo CNPq, e vinculados ao programa de Mestrado e Doutorado em Turismo e Hotelaria da Universidade do Vale do Itajaí (UNIVALI).

A opção por desenvolver estudos relativos a centros históricos se deve a relatos que mencionam o processo de globalização como responsável pela perda da memória e da identidade de algumas sociedades, em decorrência da massificação 
cultural e da dizimação do patrimônio histórico edificado das cidades, objetos que nas cidades são representados pela arquitetura e pelo traçado urbano dos núcleos históricos (Yázigi, 2001).

A criação de políticas públicas com medidas protetivas ao patrimônio histórico vem promovendo revitalizações/conservações de alguns centros urbanos e estes lugares estão sendo entendidos como lugares dinâmicos da vida urbana, animados pelo fluxo de pessoas, veículos e mercadorias, espaços que historicamente foram eleitos para sediar instituições privadas, públicas e religiosas.

O desenvolvimento tecnológico e a globalização também vêm contribuindo para que estes núcleos históricos deixem de ser o "lócus" da produção para se tornar objeto de consumo, oportunizando aos meios de comunicação e ao marketing que instaurem uma verdadeira competição entre lugares, fazendo com que a paisagem cultural destas cidades se transforme em um produto cobiçado por investidores, políticos, moradores e turistas (Vargas \& Castilho, 2009).

Dentre as mudanças tecnológicas que vêm impactando a sociedade está a internet, sua introdução tem sido significativa no comportamento organizacional e humano. A internet aproximou as pessoas e se tornou uma das principais ferramentas para o desenvolvimento de negócios, e está proporcionando oportunidades para os estrategistas de marketing alcançarem os seus clientes-alvo. Ou seja, as redes sociais, como o Facebook, vêm influenciando os hábitos de consumo e criando outras tipologias para o comércio, como o e-commerce. Estas ferramentas tornaram as empresas, inclusive as de turismo, altamente competitivas, devido à redução de custos e à falta de limites geográficos para as transações (Barrientos, 2017).

Como objeto empírico para esta investigação, foi escolhido o centro histórico da cidade de Florianópolis, um recorte desta urbe que apresenta uma superposição de layers repletos de conteúdos históricos. Esses layers começaram a ser construídos um a um. A formação do primeiro deles ocorre no ano de 1660, quando chegam os portugueses, muito outros vêm se depositando, uns sobre os outros, devido às transformações sociais, econômicas, políticas e tecnológicas que incidem sobre esta urbe. A Proclamação da República também foi um acontecimento de suma importância, pois Desterro foi promovido à cidade, ainda no século XIX essas transformações se sucedem, como mudanças urbanas vinculadas ao desenvolvimento das atividades portuárias, no século XX ocorre uma série de obras modernizadoras, relacionadas ao sanitarismo, as quais promoveram transformações na malha urbana (Cabral, 1971).

Em pleno século XXI, Florianópolis ainda é uma cidade em desenvolvimento, voltada para inovações, tanto que em dezembro de 2014 foi nomeada membro da Rede Mundial de Cidades Criativas da Organização das Nações Unidas para a Educação, a Ciência e a Cultura (UNESCO) na categoria Gastronomia (Moser e Perini, 2016); em 2017, foi considerada uma das 50 cidades mais inteligentes e conectadas do Brasil em um levantamento realizado pelo Connected Smart Cities; e no setor turístico, é um dos destinos mais visitados de Santa Catarina (Santur, 2017).

Motivados pela importante contribuição que o turismo cultural vem promovendo para a preservação/manutenção de bens patrimoniais que contam a história de 
sociedades, bens que se encontram junto a centros históricos de algumas cidades, é que este estudo se propôs a analisar as vitrines de marketing de empresas de turismo que divulgam o centro histórico de Florianópolis (SC) como um atrativo turístico, no Facebook, utilizando como metodologia os 4 A'S (acessibilidade, atração, animação e ação) da matriz do Modelo Inglês de Benchmarking e como ferramenta para análise de dados o software Iramuteq.

Vale ressaltar que foi o modelo inglês de gestão dos centros comerciais fechados, dos inícios da década de 80 do passado século, que inspirou a administração pública na resolução de problemas dos centros de cidades na Inglaterra. O Benchmarking permite identificar lacunas, quer de performance ou ao nível de procedimentos e de potenciais melhorias a serem realizadas no destino estudado (Chico, 2007).

Os resultados foram coletados durante o ano de 2019 e obtidos por meio de incursões realizadas no Facebook, junto às vitrines de Benchmarking, e-commerce, de empresas de turismo, que divulgam o turismo no Centro Histórico de Florianópolis. A coleta de dados, textos e imagens foi realizada eletronicamente, norteada pelas categorias acessibilidade, atração, animação e ação, as quais constituem os 4 A's da matriz do Modelo Inglês de Benchmarking descritas por Barrientos no ano de 2017.

A hipótese formulada, "as empresas de turismo utilizam as categorias acessibilidade, atração, animação e ação, da matriz do Modelo Inglês de Benchmarking, para elaborar as vitrines de marketing do Facebook e atrair o turista para visitar o patrimônio cultural do Centro Histórico de Florianópolis (SC)", foi confirmada. As vitrines apresentam dados, textos e imagens, da matriz dos 4 A's do Modelo Inglês de Benchmarking. Também foi observado que as informações são divulgadas sob a forma de Roteiros Turísticos, que associam os atrativos turísticos culturais do Centro Histórico a outros atrativos turísticos culturais e naturais, como paisagens e praias. Importante salientar a relevância dada à divulgação do meio de transporte terrestre e dos períodos que ele é disponibilizado.

A investigação almeja que o material produzido possa vir a contribuir com a elaboração/qualificação das vitrines de marketing de empresas de turismo que divulgam os centros históricos das cidades; que a informação gerada e divulgada por estas vitrines de marketing possa sensibilizar a outrem e estimular a criação de movimentos que resultem na criação de políticas públicas em prol da preservação/conservação do patrimônio cultural, memória e identidade de uma sociedade de uma determinada época. E que contribua com o desenvolvimento do turismo cultural, promovendo oportunidades para o crescimento da renda nas cidades - para as entidades públicas, privadas e para os residentes.

\section{O TURISMO CULTURAL E OS CENTROS HISTÓRICOS}

Ao considerar o turismo um fenômeno que envolve pessoas, demonstra-se a ligação estreita que existe entre o Estado e a sociedade e a proximidade que existe entre as pessoas e as políticas públicas. As transformações do Estado Social são orientadas pelos valores da personalidade individual e pelos valores sociais, portanto não é possível 
pensar na existência humana absorta de seus condicionantes sociais, assim como não se pode pensar em políticas públicas para o turismo sem considerar o homem e suas redes de relacionamentos, capazes de estimular a liberdade e a igualdade, conforme as diretrizes democráticas e sustentáveis (Subirats, 1994).

Sendo assim, as políticas públicas para o turismo têm como função definir os termos em que as operações turísticas devem funcionar e estabelecer a direção comum para os interessados no turismo em uma destinação; assim como as atividades e os comportamentos permitidos e permissíveis, facilitando o consenso em torno de estratégias e objetivos a serem adotados por um destino turístico. Já as ações são geridas por meio da elaboração de um conjunto de regulamentações que permite estruturar o campo de discussões sobre o papel assumido pelo turismo para a economia e para a sociedade civil, bem como a maneira que contribuirá para o desenvolvimento deste segmento (Goeldner, Ritchie \& McIntosh, 2002).

Em decorrência também das movimentações geradas pelas políticas públicas, surge a modalidade cultural do turismo no final do século XVIII e início do século XIX. Nesse momento, estava ocorrendo o desenvolvimento dos meios de transporte, propiciado pela revolução industrial; e o surgimento da classe burguesa, fator determinante para o aparecimento desta outra modalidade turística, pois essa nova classe buscou elitizar-se, não só pelo dinheiro, mas também pelo conhecimento (Barretto, 1995).

Já o despertar do turismo cultural para o sul do Brasil é muito recente, o ponto de partida para a exploração deste filão foi a conscientização dos valores da diversidade étnica que povoou e colonizou o sul do Brasil. Os Estados do Paraná, Santa Catarina e Rio Grande do Sul deram início ao turismo cultural nos anos de 90, com os programas governamentais que incentivaram as prefeituras dos municípios com concentrações étnicas de origem italiana ou alemã a explorar o seu potencial cultural promovendo festas típicas de suas tradições, atraindo significativo número de visitantes (Santos \& Goulart, 1998).

Essa modalidade turística está impondo formas atípicas para sua sobrevivência, envolvendo recursos tecnológicos avançados, shows espetaculares, mas também exigindo autenticidade nas manifestações, na busca por diferenças traçadas pela cultura, pelo patrimônio e pela natureza (Azevedo, 2002).

A clientela, cujo interesse é cultural, tem estimulado os profissionais do turismo a buscarem atrativos inovadores, a desenvolverem estratégias criativas, pois o interesse à cultura está sendo generalizado, globalizado, seu consumo está se tornando simultâneo, principalmente entre as novas gerações (Smith, 2003).

O espaço turístico cultural envolve uma série de elementos que compõe o atrativo, não se encontra individualizado, não é só a comida, a música, ou o artesanato, mas a ambiência do local onde estes encantos são consumidos, usufruídos junto à alma do lugar (Yázigi, 2001).

Portanto, a conservação do patrimônio edificado é fundamental para a manutenção da alma do lugar, local onde é possível sentir o passado, estabelecer conexões com a memória e a identidade de um povo, sua cultura. Estes bens culturais 
guardam informações, significados, mensagens, pois são os registros da história humana e refletem ideias, demonstram crenças, costumes, gosto estético, conhecimento tecnológico, condições sociais, econômicas e políticas de um grupo em uma determinada época. O patrimônio cultural edificado assume o papel de estruturador das primeiras formas e funções urbanas. Torna-se responsável pela vitalidade urbana no decorrer da história, pois nesse centro urbano se encontra uma diversidade de formas e funções, pretéritas e presentes, de signos e significados que ganharam ou perderam a importância social no decorrer do tempo (Moreno, 2002).

Estas mudanças das formas e das funções urbanas, marcadas na cidade, segundo Calvino (2011), poderiam não ter acontecido se a história vivida por aquela sociedade fosse outra, poderia não ter se tornado, por uma razão ou por outra, como se vê hoje. A cidade, o bem patrimonial, poderia estar dentro da esfera de vidro do modelo de Fedora, museificada. A museificação nem sempre é algo bom para o patrimônio. A comercialização do patrimônio cultural pode ser muito positiva, se bem dimensionada. $\mathrm{Na}$ Europa, a preservação patrimonial se tornou significativa a partir dos novos usos a eles atribuídos, possibilitando a socialização da cultura, a exemplo da Unesco, que ao classificar e comercializar o patrimônio, possibilitou a recuperação de centenas de lugares (Choay, 2011).

Qualquer processo de aproximação a um bem cultural, de qualquer natureza, pode ter seu lado positivo ou negativo. Por ser um ato crítico, as soluções fundamentadas possíveis para um dado problema são variadas; não existe nunca uma única solução plausível, aceita de maneira unânime por todos e válida em qualquer tempo, mas várias soluções de pertinência relativa. A forma de atuar junto aos bens culturais depende do modo como são indagados e percebidos e as respostas por eles dadas dependem das questões formuladas em um determinado presente histórico. É importante salientar que os preceitos teóricos permitem circunscrever, de modo pertinente, a preservação e as ações a ela relacionadas como um campo essencialmente cultural, separando-as daquilo que foge completamente de seus objetivos (Kuhl, 2009).

Com o maior desenvolvimento e integração das sociedades e também a ampliação do conceito de turismo cultural, os centros históricos estão assumindo novos contornos, adquirindo um viés integrador, uma vez que estes segmentos, ao possibilitar o contato dos visitantes com a herança cultural, reelaboram o cotidiano de comunidades, contribuindo para a difusão das culturas e para uma maior compreensão intercultural (Ascanio, 2003).

Esta preocupação com os centros históricos vem promovendo o desenvolvimento de uma consciência patrimonial que passa a revelar os antigos centros urbanos como um reflexo do presente e do futuro, muito mais que do passado, processo que vem deflagrando a formação de uma memória patrimonial que deverá responder a necessidades das sociedades do futuro. 


\section{FACEBOOK E O BENCHMARKING}

Kotler, Jatusripitak e Maesincee (1998) apontam as novas tecnologias da informação como um dos elementos fundamentais para a criação da riqueza nacional. Esta revolução da informação está se estendendo para todos os agentes econômicos e influenciando sobremaneira os custos para se obter, tratar e transmitir informações. As estratégias de Benchmarking estão atingindo a um numeroso público, reduzindo assim, significativamente, o custo de venda dos produtos.

O acesso massivo dos cidadãos e dos agentes econômicos à internet vem gerando oportunidades de melhoria na captação de negócios. A barreira geográfica, que antes dificultava estas relações, foi convertida pela excelência deste tipo de meio de comunicação. O surgimento das redes sociais, dentre elas o Facebook, tem influenciado para que os consumidores acelerem os hábitos de consumo. A internet permite que a empresa compre e venda eletronicamente, transformando o marketing e os negócios das empresas (Barrientos, 2017).

Porter (2013) entende que a internet, além de estar mudando a maneira de negociação dos produtos das empresas, vem afetando o processo de criação e redefinição de produtos, melhorando a cadeia de valores e aumentando a competitividade, outorgando maiores benefícios aos acionistas.

As mídias sociais são parte integrante desta rede e, atualmente, a maior e mais popular é o Facebook, que se tornou um importante canal de marketing, de informação e de assistência aos clientes, assim como um dos canais pelos quais as pessoas interagem umas com as outras. Segundo o relatório "Qualidade do Atendimento ao Consumidor do Brasil", divulgado no mês de novembro de 2012, esta mídia é o meio de atendimento ao consumidor mais eficiente da atualidade (Ramalho, 2012).

O Facebook é uma rede social criada em 4 de fevereiro de 2004 por Mark Zuckerberg, Dustin Moskovitz e Chris Hughes, todos alunos da Universidade de Harvard. Desde o princípio, o Facebook tem como objetivo configurar um espaço no qual as pessoas possam encontrar seus amigos e, com isso, dividir opiniões e fotografias. De sua criação até o ano de 2014, o Facebook sofreu grandes mudanças e, aos poucos, sua expansão foi aumentando até que o site permitiu que empresas também tivessem acesso à rede (Rodrigues, Simonetto, Brossarda, Del Fabro Neto, \& Löbler, 2016).

Segundo Reed (2012), o Facebook tornou-se uma das ferramentas de marketing on-line mais utilizada por empresas.com a finalidade de divulgar seus produtos ou, até mesmo, alguns eventos particulares.

\section{METODOLOGIA: OS 4 A'S DO BENCHMARKING}

O comércio eletrônico apresenta um papel muito importante na reengenharia dos negócios, automatizando os processos entre departamentos ou divisões de uma organização. Estas novas tecnologias promovem a expansão do mercado, tornando-o mais competitivo mediante as diferenciações dos produtos. Cada vez mais se implementam novos métodos que ajudam os comerciantes a ter mais facilidades para 
realizar o seu trabalho e conseguir maiores benefícios econômicos. Dentre eles está o e-commerce, que antes da integração com outras empresas exigia altos investimentos em tecnologia da informação, fato que deixou de existir devido à formação das redes de colaboração interempresariais, as quais promoveram um salto qualitativo na gestão dos negócios e da captação de clientes (Tubella \& Casadevall, 2005).

Atualmente as pessoas ingressam a internet, todos os dias, em todo o mundo. Este meio de comunicação outorga valores às suas atividades de provisão (e-commerce de compra) e de distribuição (e-commerce de venda), permitindo comercialização em nível mundial em tempo real. As métricas para medir a qualidade destes serviços estão relacionadas às funcionalidades que definem o Benchmarking de e-commerce, e indicam que cada modelo de negócio determine os seus próprios processos e tipos de transações (Jutla, Bodorik \& Wang, 1999).

Segundo Beni (1998), o sucesso do empreendimento está relacionado ao bem operar as inovações, como as ferramentas digitais, que estão sendo utilizadas em larga escala pelo setor turístico. O local de exposição dos produtos turísticos são as vitrines digitais de marketing das empresas, local onde são realizados e-commerce e social-commerce.

Com intuito de identificar como as empresas de turismo estão utilizando as vitrines de e-commerce no Facebook para divulgar o turismo no Centro Histórico de Florianópolis, incursões investigativas foram realizadas no período de abril a dezembro de 2019, quando foram identificadas 33 vitrines de e-commerce, as quais foram analisadas sob a ótica da Matriz dos 4 A's (acessibilidade, atração, animação e ação) do Modelo Inglês de Benchmarking, ver Tabela 1.

Tabela 1: Matriz dos 4 A's

\begin{tabular}{l|l}
\hline 4 A's & Subcategorias (Fatores que influenciam) \\
\hline Acessibilidade & $\begin{array}{l}\text { Circulação de automóvel e } \\
\text { estacionamento; Transportes públicos; } \\
\text { Cargas/ Descargas; Pedestres e Ciclistas; } \\
\text { Adaptação para portadores de } \\
\text { necessidades especiais }\end{array}$ \\
\hline Atração & $\begin{array}{l}\text { Arte, Cultura e Lazer; Comércio; Espaços } \\
\text { de negócios; Serviços; Habitação }\end{array}$ \\
\hline Animação & $\begin{array}{l}\text { Imagem da cidade; Ambiente urbano; } \\
\text { Espaço público; Espaço privado. }\end{array}$ \\
\hline Ação & $\begin{array}{l}\text { Promoção; Capacidade Organizativa; } \\
\text { Gestão; Recursos. }\end{array}$ \\
\hline
\end{tabular}

Fonte: Adaptada de “Comércio, Cidade e Projetos de Urbanismo Comercial”, Barreta, 2007.

O software Interface de R pourles Analyses Multi dimensionnelles de Textes et de Questionnaires (Iramuteq) foi criado em 2009 por Pierre Ratinaud. É um software gratuito de código fonte aberto, assim como os outros softwares de fonte aberta. Ele pode ser alterado e expandido por meio da linguagem Python e incorpora, além da Classificação Hierárquica Descendente (CHD), outras análises lexicais que auxiliam na análise e na interpretação de textos (Salviati, 2017). 
Os dados quantificados e a análise de similitude do material textual produzido pelas empresas de turismo foram realizados pelo software Iramuteq, um instrumento que já foi aplicado em estudos de pensamentos, crenças e opiniões produzidas em relação a determinado fenômeno e que, apesar de quantificar as palavras, realiza uma análise essencialmente qualitativa, a fim de descrever o material produzido por determinado sujeito ou sujeitos (Camargo \& Justo, 2013).

Esse programa informático, Iramuteq, pode fazer vários tipos de análises de dados textuais, no entanto, utilizada neste estudo foi a Análise de Similitude, que se baseia na teoria dos gráficos (Marchand \& Ratinaud, 2012) e possibilita identificar as coocorrências entre as palavras e seu resultado traz indicações da conexidade entre as palavras, auxiliando na identificação da estrutura da representação da ideia central dos textos.

\section{RESULTADOS}

Para Barreta (2007), autor da teoria que explica os fatores que influenciam a Matriz 4 A's, a acessibilidade do espaço urbano está relacionada a categorias como transporte público, carga e descarga, pedestres, ciclistas e adaptações do espaço a portadores de necessidades especiais.

Importante registrar que as vitrines apresentam informações sob a forma de imagens e/ou textos.

As informações textuais sobre a categoria Acessibilidade (Barreta, 2007) foram analisadas de acordo com o significado das subcategorias e quantificadas (número de vezes que a informação apareceu na vitrine), sendo elas: Circulação de automóveis e estacionamento (21) - roteiros realizados por ônibus (com vista panorâmica) pela cidade e por outra cidades próximas a Florianópolis; Pedestres e ciclistas (10) - roteiros para serem percorridos a pé/caminhadas, com e sem tempo de duração de translado. Nenhuma informação foi obtida sobre Transporte público, Carga/descarga ou Adaptação para portadores de necessidades especiais. Vale ressaltar que nos textos constavam informações sobre mais de uma subcategoria.

Nas imagens cuja Acessibilidade foi analisada, as subcategorias demonstraram: Circulação de automóveis e estacionamento (12) - mapas de parte da cidade de Florianópolis, fotografias com imagens da cidade privilegiando a vista da ponte Hercílio Luz, das vias carroçáveis com veículos de pequeno porte e de ônibus; Transporte público (02) - píer; Pedestres e ciclistas (09) - imagens de pessoas nas ruas, no centro histórico e em escadarias. Não foram encontradas informações sobre Carga/descarga ou Adaptação para portadores de necessidades especiais.

A quantidade de informações sob forma de texto sobre circulação de automóveis é muito maior, 21 vezes nos textos para 12 vezes nas imagens, relevante quando comparada com as informações fornecidas pelas imagens, ou seja, as vitrines optam menos pelos dados gráficos. A Tabela 2 denota os resultados obtidos junto aos textos e às imagens. 
Tabela 2: Análise da categoria Acessibilidade obtida em textos e imagens.

\begin{tabular}{l|l|l}
\hline Subcategoria & Textos & Imagens \\
\hline $\begin{array}{l}\text { Circulação de automóvel e } \\
\text { estacionamento }\end{array}$ & 21 & 12 \\
\hline Transporte público & - & 2 \\
\hline Pedestres e ciclistas & 10 & 9 \\
\hline Carga/descarga & - & - \\
\hline $\begin{array}{l}\text { Adaptação para portadores de } \\
\text { necessidades especiais }\end{array}$ & - & - \\
\hline Total & 31 & 23 \\
\hline
\end{tabular}

Fonte: Autores, 2020.

As informações textuais sobre a categoria Atração (Barreta, 2007) foram analisadas de acordo com o significado das subcategorias, são elas: Arte (01), Cultura e lazer (28), Comércio (02), Espaço de negócios (04), Serviços (02) e Habitações (0). Nenhuma informação foi obtida dos textos sobre a subcategoria Habitação.

Nas imagens cuja Atração foi analisada, as subcategorias demonstraram: Arte (07), Cultura e lazer (19), Comércio (07), Espaço de negócios (02), Serviços (01) e Habitação (01).

As informações textuais sobre a subcategoria Cultura e lazer aparecem em número muito maior, 28 vezes nos textos para 02 vezes nas imagens, demonstrando que as vitrines de marketing se apropriam principalmente de textos para melhor explicar estes atrativos turísticos, apesar do somatório da categoria ser idêntico sob as duas formas de apresentação.

Importante ressaltar que nos textos e nas imagens constavam informações sobre mais de uma subcategoria. A Tabela 3 denota os resultados obtidos junto aos textos e às imagens.

Tabela 3: Análise da categoria Atração obtida em textos e imagens.

\begin{tabular}{l|l|l}
\hline Subcategoria & Textos & Imagens \\
\hline Arte & 1 & 7 \\
\hline Cultura e Lazer & 28 & 19 \\
\hline Comércio & 2 & 7 \\
\hline Espaço de negócios & 4 & 2 \\
\hline Serviços & 2 & 1 \\
\hline Habitação & - & 1 \\
\hline Total & 37 & 37 \\
\hline
\end{tabular}

Fonte: Autores, 2020.

O total da quantidade de informações sobre as subcategorias, tanto em textos como em imagens, somou o mesmo valor (37). No entanto, as informações sobre Cultura e lazer, em textos (28) e imagens (19), foram mais expressivas, em número de ocorrências do que nas demais subcategorias, como já era esperado, pois o foco do contexto em análise está diretamente relacionado com o patrimônio cultural e o turismo cultural. 
As informações textuais obtidas pelo estudo sobre Animação (Barreta, 2007) foram analisadas de acordo com o significado das subcategorias e quantificadas, sendo elas: Imagem da cidade (18), Ambiente urbano (27), Espaço público (25), Espaço privado (09).

Nas imagens cuja Animação foi analisada, as subcategorias demonstraram: Imagem da cidade (19), Ambiente urbano (17), Espaço público (19), Espaço privado (13).

Importante ressaltar que nos textos e nas imagens constavam informações sobre mais de uma subcategoria. A Tabela 4 denota os resultados obtidos junto aos textos e às imagens.

Tabela 4: Análise da categoria Animação obtida em textos e imagens.

\begin{tabular}{l|l|l}
\hline Subcategoria & Textos & Imagens \\
\hline Imagem da cidade & 18 & 19 \\
\hline Ambiente urbano & 27 & 17 \\
\hline Espaço público & 25 & 19 \\
\hline Espaço privado & 9 & 13 \\
\hline Total & 79 & 68 \\
\hline
\end{tabular}

Fonte: Autores, 2020.

A diferença do somatório das informações entre os textos e as imagens foi significativa, de citadas em textos 79 vezes para ilustradas com imagens 68 vezes. Essa diferença é maior, principalmente, na subcategoria Ambiente urbano, de 27 para 17 vezes, seguido pelo Espaço público, de 25 para 19 vezes. Vale ressaltar que na subcategoria Espaço público constam informações sobre praias, junto a Espaço privado, sobre hotéis em praias. As praias da cidade de Florianópolis são atrativos turísticos de impacto nacional e internacional devido à diversidade das paisagens dessa importante ilha do estado de Santa Catarina.

As informações textuais obtidas pelo estudo sobre Ação (Barreta, 2007) foram analisadas de acordo com o significado das subcategorias e quantificadas, sendo elas: Promoção (14), Capacidade organizativa (02), Gestão (01) e Recursos (17).

Nas imagens cuja Ação foi analisada, as subcategorias demonstraram: Promoção (15), Capacidade organizativa (02), Gestão (0) e Recursos (32). As demais subcategorias apresentam números similares.

A diferença entre as informações coletadas sobre textos e imagens é significativa na subcategoria Recursos, de 17 para 31 vezes. Sendo assim, compreende-se que as imagens representam e ilustram melhor os Recursos de um destino turístico do que os textos.

Importante ressaltar que os textos e nas imagens constavam informações sobre mais de uma subcategoria. A Tabela 5 denota os resultados obtidos junto aos textos e às imagens. 
Tabela 5: Análise da categoria Ação obtida em textos e imagens.

\begin{tabular}{l|l|l}
\hline Subcategoria & Textos & lmagens \\
\hline Promoção & 14 & 15 \\
\hline Capacidade organizativa & 2 & 2 \\
\hline Gestão & 1 & - \\
\hline Recursos & 17 & 32 \\
\hline Total & 34 & 49 \\
\hline
\end{tabular}

Fonte: Autores, 2020.

Após análise dos dados quantificados, foi realizada Análise de Similitude do material textual produzido pelas empresas de turismo.

Para compatibilizar o conjunto de textos construídos pelo pesquisador com o software, os textos foram reescritos sob a forma de um corpus textual, que o transforma, segundo Camargo e Justo (2013), em um objeto para análise, como no exemplo a seguir: "*****facebook_l”.

O programa Iramuteq quantificou e estudou a associação e as coocorrências de 119 palavras, classificadas como adjetivos, advérbios, sujeitos e verbos. O número de ocorrência destas palavras varia entre 79 vezes, no máximo, e 03 vezes, o mínimo. A Tabela 6 apresenta as palavras que se repetiram até 10 vezes (decisão dos autores).

Tabela 6: Coocorrências das palavras identificadas durante a Análise de Similitude

\begin{tabular}{l|l}
\hline Palavra & Número de ocorrência \\
\hline E & 79 \\
\hline Florianópolis & 43 \\
\hline História & 21 \\
\hline Passeio & 21 \\
\hline Praia & 20 \\
\hline Tour & 19 \\
\hline Centro & 17 \\
\hline Rico & 16 \\
\hline Rio & 14 \\
\hline Ilha & 14 \\
\hline City & 14 \\
\hline Incluir & 14 \\
\hline Dia & 13 \\
\hline Mais & 12 \\
\hline Lagoa & 12 \\
\hline Aeroporto & 12 \\
\hline Transfer & 11 \\
\hline Ingresso & 10 \\
\hline
\end{tabular}

Fonte: Autores, 2020.

Este programa, Iramuteq, foi criado no idioma francês, e a versão utilizada para estas análises foi em português. Acredita-se que, devido à mudança de idiomas, algumas palavras no momento da tradução sofreram alteração. Aquelas palavras cujo significado não foi passível de compreensão foram retiradas da análise, por não existirem no idioma desta pesquisa e tampouco se relacionarem com o local deste estudo, embora permaneçam no gráfico gerado, são elas: ria, rio, m, cais e city. 
A análise de similitude, ver Figura 1, devido à aproximação das palavras gerou uma ideia central, formula da a partir dos textos encontrados nas vitrines de e-commerce, no Facebook, das empresas que divulgam o turismo no centro histórico de Florianópolis: "Os pacotes para passeio no histórico centro da cidade de Florianópolis incluem roteiros de visita a igreja, ao mercado, a ponte (Hercílio) Luz, ao mirante, além de hospedagem, guia, translado do aeroporto e brindes. O transporte (é realizado), durante o dia e a noite, para o norte e o sul da llha da Magia, (para locais) como Lagoa, Joaquina, Barra da Lagoa, Projeto Tamar, (dentre outros), incluem as dunas e são (realizados) com hora marcada". As palavras dispostas entre parênteses foram inseridas pelos autores para que haja melhor entendimento da expressão formulada. Essa ideia demonstra o senso comum encontrado nas vitrines de marketing que fizeram parte da investigação, que além da visita aos equipamentos culturais do centro histórico, incluem atrativos naturais e enfatizam o transporte e o horário que ele ocorre. É interessante a relevância atribuída ao transporte e aos horários que ele ocorre, chegando a sobrepor a importância da hospedagem (hospedagem é citada menos de 10 vezes, enquanto a palavra "transfer" é citada 11 vezes), ou seja, as vitrines enfatizam muito mais como os turistas irão se deslocar do norte para o sul da llha, de um atrativo para o outro.

Figura 1: Coocorrências da Análise de Similitude.

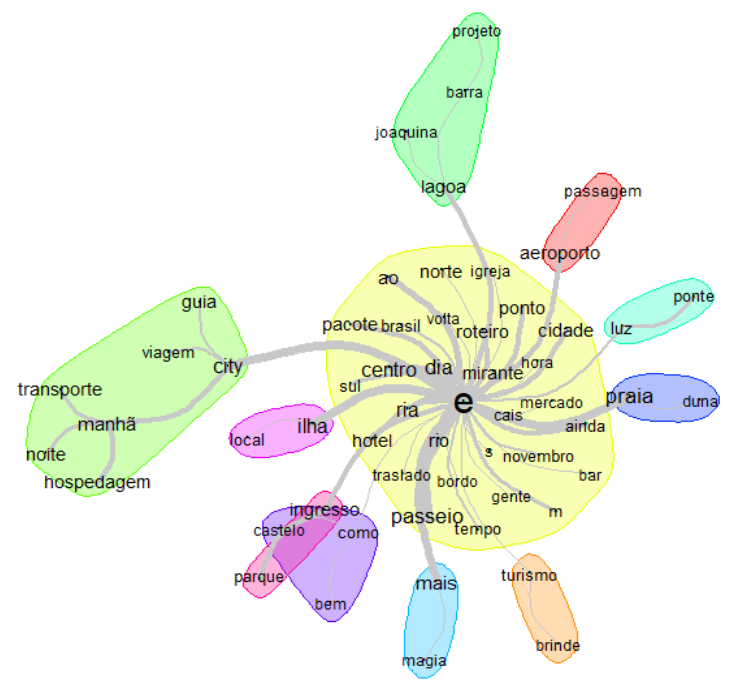

Fonte: Elaborada pelos autores no Iramuteq.

\section{CONSIDERAÇÕES FINAIS}

Esta pesquisa teve seu enfoque na trajetória do conhecimento, mais especificamente naqueles que concernem a informações relativas ao turismo cultural e suas contribuições/implicações para os centros históricos, assim como estudar táticas que estão sendo estudas e aplicadas para tornar as vitrines de marketing mais competitivas para atender ao exigente mercado, que cada dia mais se apropria de ferramentas digitais. Estar conectado às novas tecnologias é uma ação premente, pois essas inovações vêm impulsionando o crescimento de diversas áreas, inclusive as 
mercadológicas, que crescem, se modificam e se desenvolvem em virtude dos novos produtos e serviços. A cada ano surgem mais inovações do que no ano anterior $e$ cada uma tem um potencial a ser explorado maior que as anteriores. As inovações nas comunicações e nas tecnologias de computadores vêm acelerando o ritmo desta mudança, encolhendo o tempo de transmissão das informações, sendo assim, adaptar-se rapidamente ao ritmo das mudanças é fundamental para a sobrevivência dos serviços, inclusive do turismo, um mercado tão competitivo. Esta realidade vem fazendo com que empresas físicas de turismo tenham que se reinventar para enfrentar a concorrência.

As mídias digitais estão sendo utilizadas por empresas de diversas áreas como um meio para realização de novos negócios e o Facebook é uma das mídias utilizadas por elas, inclusive as de turismo (dado coletado pela pesquisa), que buscam apresentar o centro histórico de Florianópolis para potenciais turistas, consumidores de turismo cultural. As incursões às bases de dados possibilitaram o resgate de discussões sobre centros históricos, turismo cultural, os 4 A's do Benchmarking e identificar novos debates que envolvem essas temáticas, partindo de trabalhos do século XX até a atualidade. Também possibilitaram compreender como o autor dos conceitos que nortearam os 4 A'S (acessibilidade, atração, animação e ação) da matriz do Modelo Inglês de Benchmarking aplicou esta ferramenta em outros centros históricos, analisando também requisitos relacionados ao comércio e às suas relações com a segurança urbana e a vitalidade dos espaços públicos.

Ainda, refletiram sobre a importância de aplicar metodologias científicas para nortear a elaboração do material que irá compor as vitrines de marketing. As vitrines de marketing, disponíveis em meios digitais, promovem a motivação do pretenso cliente/ turista para a realização ou não da compra desta opção turística. Nela, dentre as várias informações apontadas pelas categorias dos 4 A's, devem constar também informações relativas ao patrimônio cultural, à proteção/preservação e ao uso dos bens culturais.

No decorrer do estudo, foi possível perceber que, em algumas das vitrines de marketing, o atrativo turístico aparece descrito sob a forma de um texto, fato que leva a refletir sobre a maneira que as pessoas percebem os espaços. Claro que a imaginação pode levar a viagens inimagináveis, quando se lê um texto que descreve um local. Mas os cenários criados pela imaginação podem ser diferentes da realidade descrita e gerar frustações, sendo assim, mostrar a imagem dos locais a serem visitados parece ser apropriado, podendo a imagem vir acompanhada por um texto explicativo, principalmente quando o atrativo turístico é um centro histórico, um lugar repleto de informações visuais, construídas, sejam elas objetos de qualquer natureza (edifícios, esculturas, bicas, traçados, marcas da ocupação humana e/ou de animais...). Desta maneira, ao usar a sua imagem, haverá estímulos, incitando a vontade de vivenciar aquela ambiência. Ao analisar o conteúdo dos textos foi verificado que a ênfase está na apresentação de roteiros. Estes roteiros incluem vários atrativos, naturais e culturais, além de informações sobre os patrimônios edificados de relevância histórica e cultural. Chama a atenção a importância dada ao transporte terrestre e a outros equipamentos de apoio ao turismo. Informações relevantes, que demonstram a vinculação do atrativo cultural a outros, de natureza diversa, constatação que pode indicar a insuficiência de 
atrativos culturais para motivar uma viagem, o tipo de turista (aquele que busca um passeio diversificado e não apenas cultural) ou, ainda, que as vitrines estudadas estão deixando de mostrar adequadamente o seu produto.

As constatações e as análises realizadas, em nenhum momento, tiveram a intenção de esgotar o assunto, mas de informar e estimular a realização de outros estudos, em outras mídias sociais, com outras ferramentas e colaborar para que as informações produzidas, ao serem veiculadas, contribuam com o desenvolvimento/ aperfeiçoamento das vitrines de marketing de empresas de turismo, além de colaborar com a disseminação de informações sobre a importância da preservação/conservação e da melhoria do espaço urbano de centros históricos, locais onde a história está, ali, edificada, conectando a cultural imaterial à cidade e a cidade ao turismo, gerando vitalidade, novos usos para áreas que outrora estiveram abandonadas.

\section{REFERÊNCIAS}

Ascanio, A. (2003) Turismo La reestructuraccíon cultural. In: Pasos: Revista de Turismo y Patrimônio Cultural, 01 (01). http: www.pasosonline.org.

Azevedo, J. (2002). Turismo o desafio da sustentabilidade. São Paulo: Futura.

Barreto, M. Cultura e Turismo: Discussões Contemporâneas. Campinas, SP: Papirus, 2007.

Barrientos, F. \& Barrientos, P. (2017). Marketing e internet - e-commerce: oportunidades e desafios. Revista Finanzas y Política Economica. Bogotá, 9 (1). 14718/revfinanzpolitecon.

Beni, M. C. (1998). Análise Estrutural do Turismo. São Paulo: Senac.

Cabral, O. R. (1981). Notícia Histórica, Authentica, Sincera, Pictoresca e Sentimental da Velha, depois Cidade de Santa Catharina dos Casos Raros Alcunhadas. Florianópolis, s.e.

Calvino, I. (2011). As cidades invisíveis. 14 ed. Alfragide (PT): Teorema.

Camargo, B. V.\& Justo, A. M. (2013). IRAMUTEQ: um software gratuito para análise de dados textuais. Temas em Psicologia, 21(2), 513-518. https://dx.doi.org/10.9788/TP2013.2-16

Chaffey, D.\& Smith, P.R. (2012). e-Marketing eXcellence: Planning and optimizing your digital marketing. Routledge.

Chico, F. F. (2008). Boas Práticas em Gestão de Centros Urbanos. Lisboa: Touch - Artes Gráficas, Lda.

Choay, F. (2011). As questões do patrimônio. Lisboa, Edições 70.

Goldner, C. R.; Ritchie, J. R. B.\& Mcintosh, R. R. (2002). Turismo: princípios, práticas e filosofias. 8a edição, Porto Alegre: Bookman.

Jutla, D.; Bodorik, C. \& Wang, Y. (2009) Developing Internet E- Commerce Benchmarks, Information Systems, 24 (6).

Kotler, P. Jatusripitak, S. Maesincee, S. (1998). O Marketing das nações: uma abordagem estratégica para construir riquezas nacionais. São Paulo, Futura. 
Tur., Visão e Ação, v22, n3, p597-612, Set./Dez. 2020 - Balneário Camboriú, Santa Catarina, Brasil

Kühl, B. M. (2009). Ética e responsabilidade social na preservação do patrimônio cultural. Porto Alegre. Recuperado de http://www.abracor.com.br/novosite/downloads/textobeatrizmk.pdf

Marchand, P.\& P. Ratinaud. (2012). L'analyse de similitude appliqueéaux corpus textueles: lês primaires socialistes pou rl'election présidenti elle française. Em: Actes des 11 eme Journées internationales d'Analyse statistique dês Données Textuelles. JADT 2012. (687-699). Presented at the 11 eme Journées internationals d'Analyse statistique des Données Textuelles. JADT 2012., Liège, Belgique

Moreno, J. (2020). O futuro das cidades. São Paulo: SENAC.

Moser. G. P. \& Perini, K. P. (2016) Revista Rosa dos Ventos - Turismo e Hospitalidade, 8(IV), 510-522.

Porter, D. (2013). Internet Culture. New York: Routledge.

Reed, J. (2012). Marketing Online, como usar sites, blogs, redes sociais e muito mais, 1. ed., La Fonte: São Paulo, SP.

Ramalho, J. (2012) Mídias sociais na prática, 1. ed., Elsevier, Rio de Janeiro, RJ.

Rodrigues, G. O.; Simonettoa, E. O.; Brossarda, C. S.; Del Fabro Neto, A. \& Löblera, M. L. (2016). Análise do uso do Facebook como ferramenta de marketing por empresas brasileiras de comércio eletrônico, 11 (1).

Vargas, H. \& Castilho, A. L. H. (2009). Intervenções em Centros Urbanos. $2^{a}$ edição - revisada e atualizada - Barueri, SP: Manole.

Salviati, M. E. (2017). Manual do Aplicativo Iramuteq. Planaltina, DF: Embrapa Cerrados.

Santos, R. I. C.\& Goulart, M. (1998). Uma abordagem histórico-cultural do turismo. Turismo: Visão e Ação. Itajaí, 1 (1) 19-29, jan/jun.

Santur (2017) Santa Catarina Turismo. Projeto Sinais Vitais Florianópolis. Instituto Comunitário Grande Florianópolis.

Smith, S. L. J. (2003). The tourism product. Annals of tourism Research 21 (3).

Subirats, E. (1984). A cultura como espetáculo. Trad. Eduardo Brandão. São Paulo: Nobel. 156.

Tubella, C. (2005). Societa del Coneixement. UOC, Barcelona.

Yázigi, E. (2001) Alma do lugar: Turismo, planejamento e cotidiano. São Paulo: Contexto.

COLABORAÇÃO DE CADA AUTOR NA CONSTRUÇÃO DO ARTIGO:

Diva de Mello Rossini: Coordenação da pesquisa, pesquisador de todas as temáticas abordadas e organizador do artigo.

Josildete Pereira de Oliveira: pesquisador da temática relativa aos centros históricos e turismo cultural.

Rodolfo Wendhausen Krause: pesquisador da temática relativa ao turismo cultural.

Gabriela Santos Capella: bolsita da pesquisa. 